\title{
Leadership: from classic theories to the 21th century's challenges
}

\author{
Stanca Ionela $^{1 *}$ \\ ${ }^{1}$ Department of Management, Faculty of Economics and Business Administration, University of \\ Craiova, 13 A.I. Cuza street, Craiova, Dolj 200585, Romania
}

\begin{abstract}
Permanent changes, the globalized economy, the universality of information have increased the level of competitiveness between countries in general and organizations in particular. What could be the reason why organizations competing in the same market, with similar technology and comparable resources, differ significantly from each other in terms of performance? The most limited resource in any organization is an efficient and trained person. Finding the right people for each position is critical to the company's success. Technological variations force us to learn, to adapt and to change our mentality. In order to survive, organizations need flexibility and the ability to adapt to change. It is and will be a necessary condition for employees to be the tools that provide the necessary answers that allow organizations to remain in the markets successfully over time. Leadership is the most vital, challenging and mysterious phenomenon in an organization for which researchers have worked tirelessly to explain how the best leaders perform. This article aims to review and synthesize the existing literature from the beginning to the 21th century's challenges to find the best solution for an organization's success.
\end{abstract}

\section{Introduction}

"We argue in this paper that in the age of complexity, change, big business and national states, leaders are more important than ever" [1].

The leadership process is probably the most important issue existing in an organisation, being a highly topical issue with multiple implications for the management practice and theory. It is the process that has the most extensive and decisive impact on the organisation, with the most far-reaching and conclusive consequences for organisations, on which the development, survival or disappearance of an organisation depends. In today's highly competitive environment, organisations are expanding globally and face a myriad of challenges in achieving their goals, aiming to be as successful as possible, with leaders playing a key role in achieving these goals. Facing the challenges of today's uncertain business environment makes it difficult for organisations to survive and struggle to face competitors. The success, performance and competitiveness of any organisation depends, to

* Corresponding author: stancaionela94@yahoo.com 
a large extent, on the content and quality of management, as we know that an organisation's competitive advantage lies in its people.

Organisations differentiate themselves through the people they integrate, the knowledge these people possess to be increasingly effective and better at their tasks and the way they strive to reach their full potential. In any organization, the scarcest resources are effective and well-trained and educated people; finding the right people for each position is critical to the company's success. It is not difficult to improve the technical skills of employees, what is not easy to change is the basic attitude and the way each person deals with problems and responsibilities. Caring and concern for employees is not an altruistic attitude, it is a necessity to give preference to the people who work in the organization so as to create a lasting competitive advantage.

Now, you may be wondering: How do we get employee commitment? Commitment means individual dedication and devotion, employees should be proud to work for that company. If a leader is only respected for the hierarchy he or she has in the company's organizational structure and not for his or her ability to motivate, guide and encourage employees to follow him or her, he or she is not a leader but simply a boss. The widespread acceptance that leadership plays a vital role as a competitive advantage for organizations has led to enormous amounts of spending on leadership development and training programs [2].

\section{Methods}

The literature review process is a key tool used to manage the diversity of relevant knowledge, using a comprehensive, pre-planned strategy to locate the existing literature, assess its contribution, analyse and synthesise the results and report the evidence to enable conclusions to be drawn about what is known and what is not known

Researchers and theorists have developed many different theories and approaches in their attempts to explain leadership. It has been noted that until the twentieth century, leadership research was not based on scientific inquiry [3]. The following sections include a review of the most popular leadership theories and approaches.

\section{The Great Man Theory}

Early research on leadership attempted to identify those traits that differentiated great people in history from the general masses [4]. The concern of 18th and 19th century philosophers focused on great people rather than situations [5]. The Great Man Theory assumes that leaders have unique qualities not found among the masses. It also assumes that leaders are born, not made. [6]. This theoretical perspective is considered to be the simplest, earliest and most widespread notion of effective leadership. The theory ignores the previous achievements of an organization and magnifies the greatness of the executives in the organization. In other words, the theory implies that an organization's success depends entirely on the greatness of its leadership cadre.

Within this theoretical tradition, three major reviews [4, 7-8] and two later more contemporary reviews [9-10], have explained the multiple traits considered as explanations of leadership in the early decades of development. Common traits in these reviews were intelligence, self-confidence, honesty, integrity, and interpersonal sensitivity. Age, weight or height were not found to be related to leadership. Throughout history, great figures have lived, each, not necessarily with the same defining characteristics that leaders must have and those who do not have them are not leaders. Each character has their own qualities.

\section{Character traits approach to leadership}


In the first half of the 20th century, trait theory was considered the dominant theory of leadership [3]. The trait approach attempted to determine the personal, psychological and physical traits of strong leaders.

The theory argued that if leaders were endowed with superior traits or characteristics that differentiated them from their followers, it should be possible for these traits or characteristics to be isolated [11].

In a classic review of the leadership literature, [8] reviewed 124 studies on leadership traits. The purpose of the review was to examine the relationship between the trait approach and effective leadership. As a result, Stogdill found that there are certain characteristics (intelligence, physical, social environment, personality, and task-related characteristics) that can be used to distinguish leaders from non-leaders. His results revealed little or no relationship between other characteristics and effective leaders. They also led Stogdill to realize the importance of situational variables in determining effective leadership. Overall, Stogdill's conclusion did not support the study of trait theory as the sole approach to leadership research. He concluded that an individual does not become a leader by having a specific blend of attributes, but the leader's pattern of personal attributes must be related to the features, activities, and goals of followers. Thus, leadership must be conceived in terms of the interplay of variables that are constantly changing and in flux. The persistence of individual patterns of human behaviour in the face of constant situational change seems to be the main obstacle encountered not only in the practice of leadership but also in the selection and placement of leaders [8].

\section{The behavioural approach to leadership}

In the 1950 s, once researchers noticed that trait theory was not an adequate approach to explaining leadership effectiveness, they began to focus on the behavioral traits of leaders. Specifically, they began to focus on what the leader does and how he or she does it [12]. The type of behavior that can influence members of a group is the main concern of this approach. It is not a normative view, but a description of the behavioural components that leaders exhibit that generate influence [13]. Thus, even though different theories have emerged, they have all mainly recognised two general types of behaviour: task-oriented and people-oriented. Two significant studies in leadership were conducted at Ohio State University and the University of Michigan in the 1960s.

The Ohio State University studies, some of the best known, proposed different styles of leadership, with the basic expectation that there is a reliable alternative to both taskoriented and people-oriented leadership. The purpose of their studies was to determine the types of behaviors leaders exhibit and to determine the effects of leadership style on work group performance and satisfaction [14]. Initially, the researchers developed a list of over 1,000 leadership behaviors. In these studies of leadership behaviours, Ohio State University researchers have not been able to adequately identify the most effective leadership style. Moreover, the belief that high regard and high initiating structure lead to effective leadership could not be proven true in all studies. Results varied and no style emerged as the best. As a result, this approach has also received much criticism from researchers in the field. However, despite the obvious weaknesses, the importance of these efforts should not be diminished. The contributions of the Ohio State University have provided significant building blocks in the evolution of a theory that has enabled the description of leadership behaviours. Indeed, these studies served as the foundation on which subsequent research was built [12\}]

The method of the University of Michigan research was to study the relationships between leader behavior, group process, and group performance measurement. As at the Ohio State University, the University of Michigan researchers developed two distinct leadership styles, labeled as production-centered and employee-centered leadership styles 
[15]. The Michigan studies showed that leaders with a production-centered leadership style emphasized close supervision, legitimate and coercive power, routine, and performance. This style was seen as similar to the Ohio State University dimension of initiating structure. Leaders with an employee-centred leadership style were described as being more concerned with their subordinates as individuals. These leaders recognized the needs of followers, such as well-being, advancement, and growth. Similarly, the Ohio State University dimension of consideration described similar behaviors [12].

Likert proposed a new system based on improving workers' potential and motivation. For this system, he developed a questionnaire to measure aspects of a leader's behaviour: motivation, communication and decision-making. With this he conducted studies with his colleagues Katz, McCoby, Kahn and Seashore [16-17] at the University of Michigan in 1947 to determine the methods of effective leadership vital to achieving desired performance and satisfaction.

The Blake and Mouton managerial grid focuses on the orientation of managers toward tasks (production) and toward people, as well as combinations of the two extremes. This grid is recognised as a balanced one that denotes dimensions of managerial responsibility. A grid with concern for production on the horizontal axis and concern for people on the vertical axis outlines five basic management/leadership styles. The first number refers to a leader's production or task orientation and the second to people or employee orientation. Task management equals team management - a high concern for both employees and production has been proposed as the best and most effective type of leadership behaviour. The theory assumes that managerial behaviour is conditioned by subjective judgements or assumptions acquired from childhood through experience. These assumptions can be changed by identifying and acknowledging them, gaining new experiences and being open to opinions [18-21]. Leaders, through modeling, can locate the assumptions or leadership style they exercise and learn the leadership behaviors or new assumptions needed for better performance. Socialization and early learning are also considered important elements in the development of transformational leaders [22-23].

\section{Situational approach to leadership}

The situational approach stresses the importance of contextual factors influencing leadership processes [24]. The assumption behind the theory is that different situations require different leadership styles [13]. Earlier theories recognized the effects of situations on the leadership process, which gave rise to two major lines of research since the 1960s. The first focused on studying how situations affect leadership style and, second, how leadership styles are related to performance indicators in different situations.

As in the previous approach, situational theorists define leadership in terms of observable behaviors, but when operationalizing the concept, they place greater emphasis on the leadership styles that are generated along with them and the interaction of these styles with different situational variables [25-27]. However, there is a consensus in considering leadership as the process of interaction between the behaviours a person displays when trying to influence the behaviour of others to achieve common goals and the different personal situations, followers, work or social, economic or political environment that are conditioned to leadership effectiveness. Research at Ohio University [8, 28-29] and Michigan University [31] has already considered the possibility that situations have moderating effects on leadership behaviors.

\section{Recent theories of leadership styles}

A leadership style can be defined as one's technique or way of giving direction, implementing plans and motivating people. This section identifies several leadership styles 
that leaders portray intentionally or unintentionally in a group. These include autocratic, democratic, laissez-faire, transactional, transformational and charismatic leadership styles.

Autocratic leadership, also known as dictatorship, is where the leader is the focal point of power and considers their own decisions and judgement to be supreme [32-33]. The style is grounded in transactional theory, which emphasises the relationships that exist between leaders and their followers. In this case, followers simply take orders; the style is devoid of member participation because members are not consulted [33-35]. Members are motivated to obey leadership or perform because of reward systems and punishments for noncompliance $[32,35]$. The disadvantages of autocratic leadership seem to outweigh the advantages. Followers perform because of reward or punishment systems for noncompliance $[32,35]$. The disadvantages of autocratic leadership seem to outweigh the advantages. For this reason, autocratic leadership style is not popular among employees (and colleagues) in most organisations. If it is used in organisations, leaders may apply it accidentally.

Democratic leadership style, also known as participative leadership style, has its roots in transformational theory [32-33, 35]. In this case, leadership focuses on change, visionary leadership and improving individual and organisational outcomes. Members are given the opportunity to develop their leadership skills, participate in leadership and contribute to decision-making [33]. It is arguably more effective than autocratic leadership [36]. Employees feel that their opinions, suggestions and ideas are taken into account. Although members enjoy a certain level of autonomy, it works effectively in situations where members are highly skilled, passionate and more satisfied with their work, such as the situation where laissez-faire leadership style is used.

The charismatic leadership style is rooted in a form of boldness, courage or extreme personality, more or less of celestial origin [32, 37]. It is one of the leadership styles proposed by Max Weber in 1947. It assumes that charm and grace result in a large following, self-confidence is a fundamental need of leaders, and members follow those leaders they hold in high esteem, rather than any external form of power [39-40]. Charismatic leadership style is quite common in church organizations.

Transformational leadership, due to the components of idealized influence, inspiration, intellectual stimulation, and individualized consideration, has been suggested as the optimal style for managing change. Bass, Waldman, Avolio, and Bebb [41] found that leaders who score higher on the factors of transformational leadership have followers who exhibit higher levels of transformational behaviors. Many studies have shown that transformational leadership is most preferred by an organization's employees. Burns [23] defined transformational leadership as "a process by which leaders promote the motivation of their followers to pursue and achieve goals higher than the collective interest of the group". Bass [42] discussed that transformational leaders act cooperatively with employees, commit to their crucial needs, and encourage them to move in a particular direction. Transformational leaders, as defined by Burns [23] and Bass [22], are those who use their position of power not only to give direction but succeed in elevating the needs of their followers to higher hierarchical levels. They want their followers to be aware of the importance of the tasks they perform in order to improve their performance, aligning their personal interests with those of the organization and arousing higher-order needs.

Transactional style works best for those jobs that require less skilled employees, i.e., when team members are low skilled. In these cases, the boss indicates the functions that each person must perform, sets a goal, an objective and is remunerated according to it, as the goal is exceeded, the remuneration increases accordingly. It has the disadvantage that the work can be detrimental to its quality if workers, in the desire to achieve and exceed the set goal, neglect the accuracy and dedication of their activities. Burns [23] referred to transactional leadership as one that focuses on the changes that occur between leaders and 
their followers. Similarly, managers who give raises to employees who exceed their goals exhibit transactional leadership. The change aspect of transactional leadership is pervasive and can be seen at many levels in all types of organisations. This leadership style focuses on achieving the goals of the given job. The fundamental concept of transactional leadership is that understanding the relationship between effort and reward, responsiveness to expose problems, use of incentives, rewards, punishments, motivating goal setting and rewarding performance, and use of power to compel followers to accomplish tasks [23].

While transactional and transformational leaders have been described as active leaders [43], laissez-faire leaders have been considered inactive. Laissez-faire leaders are characterized by the avoidance of accountability and decision-making. A leader who avoids or does not intervene in work tasks or avoids responsibility entirely and does not guide or support followers can be considered a laissez-faire leader. This style of leader is likened to dissatisfaction, unproductivity and ineffectiveness. This style of leadership allows subordinates to make their own decisions because the leader does not manifest real authority. The leader only answers questions and provides information or offers support to the group. Laissez-faire leadership has a negative impact on subordinates' work performance [44-45].

\section{Results}

Since the 18th century, leadership has been a subject of interest. However, the field of leadership was not studied scientifically until the early 20th century. The first research on leadership attempted to identify leadership through a theoretical approach. The Great Man Theory assumed that leaders are endowed with unique qualities not found in the masses. Trait theory, considered to be the dominant theory of leadership in the first half of the 20th century, attempted to determine the personal, psychological and physical traits of strong leaders. During the 1950s, the theoretical approach was abandoned because of its inability to explain leadership effectiveness. As a result, the behavioural theory represented by studies at Ohio State University and the University of Michigan took hold. The behavioral approach simply sought to identify certain types of behaviors that leaders exhibit and determine the effects of these behaviors on subordinates. In the 1960s, leadership researchers focused their attention on situational factors and their effects on leadership effectiveness. Situational or contingency theories argued that there is no universal leadership behaviour that can be applied in all situations. The full range of leadership that included three styles (transformational, transactional and laissez-faire) is a recent development in the field. This approach integrated ideas from trait, behavioural and situational theories and built on them. Transformational leaders inspire followers to rise above self-interest for the greater good of the group and do more than initially expected. Transactional leaders focus on clarifying task requirements and specifying contingent rewards.

It is recognized that there is no standard definition for leadership; its appropriateness depends on the researcher's purpose. According to Bass and Avolio [42], a single specific definition of leadership is a very complex task because the literature and studies on the subject are varied and there is no universal or widely accepted definition. Some definitions describe leadership as an act of influence, some as a process and others have turned to the qualities and traits of individuals.

\section{Conclusion}


When a leader decides to take action, the starting place should be the employees, improving the relationship with them, making their lives easier, facilitating and providing the resources they need in order to develop and reach their potential. A leader's task is to ensure that employees are protected and to see each person as capable of making a significant contribution.

Taking into account the problem of the task, the authority of the leader, the maturity and skill of the subordinates, the ingredients of effective leadership are complex, and it is widely accepted that they depend on precise leadership. Leadership skills generally take time to be discovered. Becoming an effective leader can be a challenge for some new managers. Understanding the principles of strategic thinking, direction setting, communication, and motivation provides a springboard for developing good management skills and styles that match personality and leadership situations.

For Heike and Walter [46], the literature was found to be totally lacking in studies that provide a comprehensive treatment of leadership at different hierarchical levels. According to Oberg the degree of devotion and trust that the leader inspires in the follower enables him to overcome his own limitations and identity towards a state of full health. The engine that sets people in motion are goals, visions, dreams; a leader should be an emitter of dreams, convincing his employees that they are capable of doing exceptional things. They get to know the nature of people, arouse passion among them and shape people capable of leading, especially in tense and pressured times. That's why consistency between their words and deeds is a quality that helps to mitigate those unpleasant moments.

The leadership style used by managers is the most common factor that can influence an employee's attitude and behaviour, leading to improved organisational performance. That said, managers are able to influence their subordinates, which leads to more engaged and satisfied employees, which in turn leads to increased productivity. People are increasingly articulate and educated; they need a participatory environment and greater inclusion in decision-making. Without the motivational capacity of the leader, the behavioural components and their adaptability to the situation will not work. Without achieving this goal, followers will not be able to turn their vision into a concrete reality.

This paper's goal was not only to contribute to a better understanding of the concepts, statements and conceptual frameworks by analyzing and reviewing the existing literature but also to have practical implications for those in managerial positions and find effective strategies of improving leadership skills.

"Leadership is about methods, not magic" [47].

\section{References}

1. R. J. House, W. D. Spangler, J. y Woycke, Adm. Sci. Q., 36(3), 364-396 (1991)

2. B. J. Avolio, S. T. Hannah, CPJ, 60, 331-347 (2008)

3. M. M. Chemers, An Integrative Theory of Leadership, (Publisher: Lawrence Erlbaum Associates, New York, 1997)

4. R. M. Stogdill, Handbook of leadership: A survey of theory and research, 1a. Ed., (New York: Free Press, 1974)

5. J. V. Spotts, The problem of leadership: A look at some recent findings of behavioural science research (1964)

6. D. A. Kolb, I. M. Rubin, J. M. Mclntyre, Organizational Psychology: An Experiential Approach, (Englewood Cliffs, NJ: Prentice-Hall, 1971)

7. R. D. Mann, Psychol. Bull., 56(4), 241-270 (1959)

8. R. M. Stogdill, J. Psychol., 25, 35-71 (1948) 
9. S. A. Kirkpatrick, E. A. Locke, Acad. Manag. Perspect.,5(2), 48-60 (1991)

10. R. G. Lord, C. De Vader, J. Appl. Psychol., 71(3), 402-410 (1986)

11. B. M. Bass, Stogdill's Handbook of leadership: Revised and expanded edition, (New York: The Free Press, 1981)

12. J. M. Ivancevich, Jr. A. D. Szilagyi, Jr. M. J. Wallace, Organizational Behaviour and Performance, (Goodyear Publishing Company Inc., 1977)

13. P. G. Northouse, Leadership: Theory and Practice, Thousand Oaks: (SAGE Publications, 2007)

14. E. A. Fleishman, A leader behavior description for industry, In R.M. Stogdill, A.E. Coons (Eds.), Leader Behavior: Its description and measurement, Columbus: Ohio State University, Bureau of Business Research, Monograph № 88, 103-119 (1957a)

15. M. A. Ansari, Managing People at Work: Leadership Styles and Influence Strategy, Sage Publication, (New Delhi/London, 1990)

16. D. Katz, R. L. Kahn, The social psychology of organizations (2nd ed.), (New York: Wiley, 1978)

17. D. G. Bowers, S. E. Seashore, Adm. Sci. Q., 11(2), 238-263 (1966)

18. R. R. Blake, J. S. Mouton, The managerial grid, (Houston: Gulf Pub, 1964)

19. R. R. Blake, J. S. Mouton, An overview of the grid, Train Dev J, 29(5) (1975)

20. R. R. Blake, J. S. Mouton, The New managerial grid, (Houston: Gulf Pub, 1978/1980)

21. R. R. Blake, J. S. Mouton, Management by grid ${ }^{\circledR}$ principles or situationalism: Which?, GOM: SAGE J (1981)

22. B. M. Bass, Leadership and performance beyond expectations, (Free Press: New York, 1985)

23. J. M. Burns, Leadership, (Harper \& Row, New York, 1978)

24. G. A. Yukl, Leadership in organizations (7ma. Ed.), Upper Saddle river, (NJ: Prentice Hall, 2009)

25. F. E. Fiedler, A theory of leadership effectiveness, (New York: McGraw-Hill, 1967)

26. W. J. Reddin, Train Dev J, 23(5), 8-17 (1967)

27. P. Hersey, K. H. Blanchard, D. E. Johnson, Management of organizational behavior: leading human resources (9na. Ed.), Upper Saddle River, (NJ: Pearson Prentice Hall, 2007)

28. E. A. Fleishman, J. Appl. Psychol, 37(3), 1-6 (1953)

29. J. K. Hemphill, Educ. Res. Bulletin, 28(9), 225-229 (1949)

30. R. Likert, A new method of management and direction, (Bilbao: Deusto, 1961/1965)

31. R. Likert, R., The human factor in the company: Its direction and assessment, (Bilbao: Deusto, 1968)

32. C. S. Burke, K. C. Stagl, C. Klein, G. F. Goodwin, E. Salas, S. M. Halpin, Leadersh. Q., 17(3), 288-307 (2006)

33. E. Vigoda-Gadot, Pers. Rev., 36(5), 661-683 (2007)

34. A. M. Rad, H. M. Yarmohammadian, LHS, 19(2), 11-28 (2006)

35. S. Vesterinen, A. Isola, L. Paasivaara, J. Nurs. Manag., 17(4), 503-509 (2009)

36. J. MacBeath, Sch. Leadersh. Manag., 25(4), 349-366 (2005)

37. B. J. Avolio, F. O. Walumbwa, T. J. Weber, Annu. Rev. Psychol., 60, 421-449 (2009) 
38. M. Weber, The Theory of Social and Economic Organization, Glencoe, (IL: Free Press, 1947)

39. J. Lee, Leadersh. Organ. Dev. J., 26(8), 655-672 (2005)

40. S. T. Hannah, B. J. Avolio, F. Luthans, P.D. Harms, Leadersh Q, 19(6), 669-692 (2008)

41. D. M. Bass, D. A. Waldman, B. J. Avolio, M. Bebb, GOM: SAGE J, 12(1), 73-87 (1987)

42. B. M. Bass, B. J. Avolio, Full range leadership development manual for the multifactor leadership questionnaire, (Palo Alto, CA: Mind Garden, 1997)

43. F. Yammarino, B. Bass, Hum. Relat., 43(10), 975-995 (1990)

44. B. J. Avolio, D. A. Waldman, W. O. Einstein, GOM: SAGE J, 13(1), 59-80 (1988)

45. B. M. Bass, B. J. Avolio, ROCD,4, 231-272 (1990)

46. B. Heike, F. Walter, Leadersh. Organ. Dev. J., 28(8), 710-726 (2007)

47. M. Schmoker, The results fieldbook: Practical strategies from dramatically improved schools, Alexandria, VA: Association of Supervision and Curriculum Development (2001) 